Results: The melatonin serum levels in RA patients were in 2 and 3 times higher in the morning and evening time than those of healthy individuals in the control group $(p=0.001)$. We noticed significant correlations between melatonin level and disease duration $\left(r_{S}=-0.5, p<0.01\right)$. Significant differences in melatonin levels were revealed in RA patients in $1^{\text {st }}$ and $3^{\text {rd }}$ groups $(p=0.049)$, in $1^{\text {st }}$ and $4^{\text {th }}$ groups $(p=0.012)$, in $2^{\text {nd }}$ and $3^{\text {rd }}$ groups $(\mathrm{p}=0.001)$, in $2^{\text {nd }}$ and $4^{\text {th }}$ groups $(\mathrm{p}=0.001)$. Also we determined significant differences in melatonin levels between $1^{\text {st }}$ and $2^{\text {nd }}$ radiological stages $(p=0,001)$ of RA patients. However, melatonin levels were not related to physical activity (HAQ). Conclusion: We found a close relationship between serum melatonin levels, duration of the disease and radiological progression in RA patients. The most significant changes in melatonin metabolism occur in patients with the duration of the disease up to 5 years and with lower radiological stages. Our data indicate the important role of neurotransmitter in the pathogenesis of RA, especially at the initial stage of the disease.

REFERENCES:

[1] Sternberg EM. Neuroendocrine regulation of autoimmune/inflammatory disease. J Endocrinol. 2001 Jun;169(3):429-35. doi: 10.1677/joe.0.1690429. PMID: 11375112

[2]Mańka S, Majewska E. Immunoregulatory action of melatonin. The mechanism of action and the effect on inflammatory cells. Postepy Hig Med Dosw (Online). 2016 Oct 4;70(0):1059-1067. doi: 10.5604/17322693.1221001. PMID: 27708210.

Disclosure of Interests: None declared

DOI: 10.1136/annrheumdis-2021-eular.3752

\section{POS0499 WORK ABSENCE DUE TO MUSCULOSKELETAL SYMPTOMS IN PATIENTS AT-RISK OF RHEUMATOID ARTHRITIS IS COMPARABLE TO THOSE WITH ESTABLISHED DISEASE}

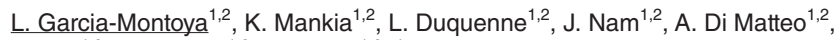
J. Peill ${ }^{1,2}$, E. Mumba ${ }^{1,2}$, P. Emery ${ }^{1,2}$. ${ }^{1}$ Leeds Institute of Rheumatic and Musculoskeletal Medicine, University of Leeds, Leeds, United Kingdom; ${ }^{2}$ Leeds Biomedical Research Centre, NIHR, Leeds, United Kingdom

Background: Rheumatoid arthritis (RA) is an established cause of disability and work absence; however, little is known about the impact of musculoskeletal (MSK) symptoms on sick leave in patients at-risk of developing the disease. Objectives: To describe the sick leave of individuals at-risk of RA, compared to patients who had recently been diagnosed with RA, over a 12-month period. Additionally, to investigate baseline predictors for sick leave within the first 12 months.

Methods: A prospective observational cohort for individuals at-risk of RA was conducted. A total of 591 consecutive anti-citrullinated protein antibodie positive $(\mathrm{ACPA}+)$ individuals, with no clinical synovitis were recruited. A MSK ultrasound scan and a blood test were performed at baseline, and information about employment regime (retired, not in a paid job, part time and full time), days of sick leave and reasons for absences within the previous months were collected every 3 months and analysed at baseline, 6 months, 12 months and at the moment of diagnosis of an inflammatory arthritis (IA) (if the patient had progressed). Subjects who had retired $(n=80)$ were excluded from the analysis.

A comparison was made with 114 RA patients from an observational study. Employment information was collected at pre-treatment, 6 months and 1 year after diagnosis Univariable and logistic regression analyses were performed to assess predictors of work absence due to MSK reasons in the next 12 months from baseline for at-risk individuals.

Results: Even though the reasons for unemployment were not available, there were no statistically significant differences between employment rates across the timepoints of the study for the at-risk individuals' group $(p=0.778)$. A similar pattern was observed in the RA patient group; which also maintained the same employment rates throughout the study $(p=0.311)$ and these were comparable to the at-risk individuals' ( $p=0.480)$.

Over $35 \%$ of at-risk individuals in paid employment had work absences in the 3 months prior to the baseline visit. Of these $65.5 \%$ were due to MSK related issues, meaning $23.2 \%$ of the total absences were MSK related. The other reasons for work absence can be seen in table 1 . This fell to $12.9 \%$ of the total absences at 6 months (which probably reflects clinical intervention) and increased to $38 \%$ if the patient progressed to an IA (graph 1).

Table 1. REASONS FOR SICK LEAVE AT BASELINE IN INDIVIDUALS AT-RISK OF RA (\%)

MSK related issues

Flu-like symptoms

Gastrointestinal issues

Stress/anxiety

Headaches

Infection

Fatigue

Othe
The percentage of individuals who took absence from work due to MSK related issues, was similar in both the at risk and RA group, including an initial reduction possibly due to drug intervention (graph 1). However, the median number of days off work 3 months prior baseline, 6 months and 1 year in RA patients tended to be higher than those in the at-risk group (10, 2 and 6 versus 5,4 and 3 respectively).

Several factors were assessed to predict sick leave within 12 months in at-risk individuals: age, gender, smoking status, ACPA, rheumatoid factor (RF), anti-nuclear antibodies (ANA), C-reactive protein (CRP), early morning stiffness, shared epitope, joint pain, joint tenderness and abnormal findings in the ultrasound scan (erosions or power doppler); however, only RF [OR 0.18; $p=0.018 ; 95 \% \mathrm{Cl}(0.04$ $0.84)]$ and CRP [OR $1.3 ; p=0.021 ; 95 \% \mathrm{Cl}(1.04-1.60)]$ were statistically significan in the multivariable analysis.

Conclusion: Even though being at-risk of RA is not considered a potentia cause of disability, results show that the burden on the workplace, due to MSK related absences, was comparable to subjects diagnosed with RA. Although fur ther investigation is required, initial data suggests that clinical intervention may reduce this burden; which tends to be higher in at-risk individuals with a negative RF and a high CRP.

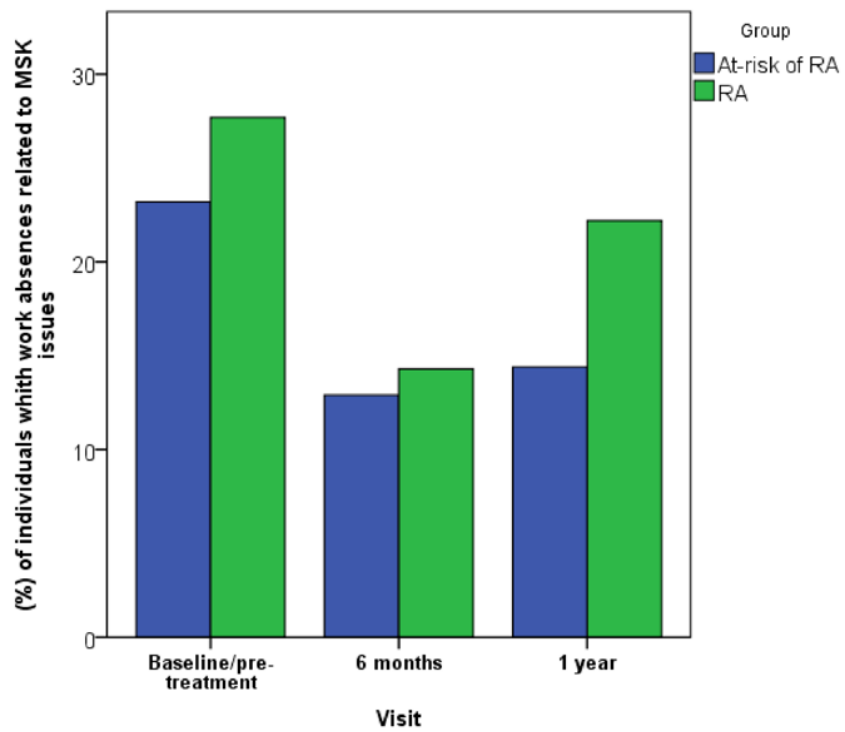

Graph 1. Percentage of individuals who had work absences related to MSK issues 3 months prior to each timepoint.

Acknowledgements: $\mathrm{H}$. Singh

T. Hulland

G. John

- Leeds Cares -

Disclosure of Interests: None declared

DOI: 10.1136/annrheumdis-2021-eular.3765

\section{POS0500 NUMBER AND CO-EXPRESSION OF TNF RECEPTORS TYPE 1 AND 2 ON IMMUNOCOMPETENT CELLS ARE ASSOCIATED WITH STABILITY OF REMISSION IN RHEUMATOID ARTHRITIS PATIENTS}

A. Alshevskaya ${ }^{1}$, J. Lopatnikova ${ }^{1}$, J. Zhukova ${ }^{1}$, O. Chumasova ${ }^{2}$, N. Shkaruba ${ }^{2}$, A. Sizikov ${ }^{2}$, S. Sennikov ${ }^{1,3} .{ }^{1}$ RIFCI, Laboratory of Molecular Immunology, Novosibirsk, Russian Federation; ${ }^{2}$ RIFCl, Rheumatology Department, Novosibirsk, Russian Federation; ${ }^{3}$ Novosibirsk State University, Institute of Medicine and Psychology, Novosibirsk, Russian Federation

Background: The balance of TNF $\alpha$ receptors expression on cells which are actively involved in immunopathological processes affects both the density of distribution of receptors on cells and co-expression in subsets. Previously it was shown that basic effective RA therapy with methotrexate and glucocorticoids leads to equalization of the expression profile either in the percentage of cells or in the number of receptors, approaching those of healthy donors, but not simultaneously. However, questions about the relationship between the effectiveness of biological therapy and receptors co-expression remain unknown.

Objectives: To assess the differences in co-expression and quantitative expression of TNF receptors type 1 and 2 in subsets of cells associated with the severity of the disease, depending on the response to rituximab therapy.

Methods: Subanalysis of patients with high disease activity level successfully treated with rituximab (alone or in combination treatment scheme) during 